\title{
Perforación faringoesofágica espontánea complicada con absceso mediastinal en niño
}

\section{Spontaneous pharyngoesophageal perforation complicated with mediastinal abscess in childrens}

\author{
Rogelio Sancho-Hernández,* Lizbeth Solorio-Rodríguez, \\ Lourdes Mascareñas-Martínez,* José Ariel Castillo-Moguel*
}

*Instituto Nacional de Pediatría, Ciudad de México; `Pediatría Integral y Terapia Respiratoria, Toluca, Estado de México.

RESUMEN. Introducción: La perforación faringoesofágica representa una condición crítica con altas tasas de morbilidad y mortalidad asociada a un diagnóstico tardío; las actuales recomendaciones abogan por un tratamiento conservador. El presente reporte describe la utilidad del manejo endoscópico y conservador de una paciente con perforación faringoesofágica espontánea complicada con absceso mediastinal. Se detalla el beneficio de los adhesivos tisulares en el cierre de una fístula residual y se propone una revisión de la literatura aplicada a la población pediátrica. Descripción del caso: Adolescente femenino de 16 años quien acudió al servicio de urgencias con disfagia, fiebre y enfisema subcutáneo cervical y torácico; en la esofagografía y tomografía se corroboró perforación esofágica superior y presencia de un absceso mediastinal. Por considerar la vía transendoscópica insuficiente para el drenaje de la cavidad mediastinal septada se realiza un abordaje cervical posterior izquierdo que permite un desbridamiento mecánico y el drenaje de $600 \mathrm{~mL}$ de material purulento. Ya con mejoría clínica persiste con una fístula faringocutánea mediastinal, se instila entonces por vía endoscópica transcatéter una solución de adhesivo tisular en el interior de todo el doble trayecto fistuloso y posteriormente se cierra con evolución favorable. Conclusiones: Un reconocimiento temprano de la perforación faringoesofágica así como el desbridamiento agresivo y el apropiado drenaje permiten que los adhesivos tisulares como el cianoacrilato promuevan por la vía transendoscópica un cierre exitoso y de baja morbilidad en las secuelas y fístulas secundarias.

Palabras clave: Perforación esofágica, absceso mediastinal, tratamiento endoscópico, adhesivo tisular.
ABSTRACT. Introduction: Pharyngo-esophageal perforation represents a critical condition with high morbidity and mortality rates associated with a late diagnosis, current recommendations advocate conservative treatment, this report describes the usefulness of conservative and endoscopic treatment of a patient with spontaneous pharyng-esophageal perforation complicated with mediastinal abscess, the benefit of tissue adhesives in the closure of a residual fístula is detailed and a review of the literature applied to the pediatric population is proposed. Description of the case: A 16-year-old female adolescent who attended the emergency department with dysphagia, fever and subcutaneous emphysema of the neck and thorax, in esophagography and tomography, an upper esophageal perforation and the presence of a mediastinal abscess were corroborated, as the trans endoscopic route was considered insufficient for the patient a drainage of the septate mediastinal cavity and a left posterior cervical approach was decided, allowing mechanical debridement and drainage of $600 \mathrm{ml}$ of purulent material; with clinical improvement, it persists with a pharyngo-cutaneous-mediastinal fístula and the decision was made to instill a solution of tissue adhesive inside the entire double fistulous tract and successful successful closure with a favorable evolution. Conclusions: An early recognition of pharyngoesophageal perforation, as well as aggressive debridement and appropriate drainage, allow tissue adhesives such as cyanoacrylate to promote successful and low morbidity closure by trans endoscopic in secondary sequelae and fistulas.

Keywords: Esophageal perforation, mediastinal abscess, endoscopic treatment, tissue adhesive.

\section{INTRODUCCIÓN}

La perforación faringoesofágica representa una condición crítica con altas tasas de morbilidad y mortalidad de 10 y $35 \%$, respectivamente. Aun cuando la perforación de una víscera hueca deberá ser tratada de manera quirúrgica, las actuales recomendaciones abogan por el tratamiento conservador de las perforaciones esofágicas cervicales., ${ }^{1,2}$ Los factores que influyen en el pronóstico y determinan los algoritmos de actuación y tratamiento quirúrgicos son la localización y etiología de la perforación y la presencia o ausencia de absceso mediastinal, ${ }^{2,3}$ aunque la instaura- 
ción temprana de un tratamiento conservador o quirúrgico parece ser el predictor más importante en la sobrevida..$^{3-5}$ El tratamiento conservador incluye administración de antibióticos de amplio espectro, ayuno con nutrición parenteral y drenaje de la cavidad cervical y mediastinal abscedada. Recientemente este drenaje ha sido reportado bajo visión endoscópica con la inserción de catéteres y la aplicación de stents y/o clips en el sitio de la perforación esofágica, o bien punción evacuadora guiada por ultrasonografía o tomografía y posterior cierre espontáneo de la perforación. ${ }^{3,6-8}$

El presente reporte de caso describe la utilidad del manejo endoscópico y conservador de una paciente con perforación faringoesofágica espontánea complicada con absceso mediastinal de causa inusual. Se detalla el beneficio de los adhesivos tisulares en el cierre de una fístula faringocutánea residual y se propone una revisión de la literatura aplicada a la población pediátrica.

\section{PRESENTACIÓN DEL CASO}

Paciente femenino de 16 años que inicia con vómitos y evacuaciones diarreicas secundario a gastroenteritis infecciosa, más tarde con aumento de volumen y dolor en región cervical izquierda, acudió al servicio de urgencias con disfagia, fiebre y enfisema subcutáneo cervical y torácico superior. En la radiografía cervicotorácica se identificaron enfisema subcutáneo, ensanchamiento mediastinal y neumomediastino. Una serie esofagogastroduodenal documenta fuga de material de contraste a nivel del esófago superior con extensión a mediastino con impresión diagnóstica de perforación esofágica cervical izquierda espontánea con compromiso mediastinal (Figura 1).

Se descartan antecedentes de ingestión o aspiración de cuerpo extraño, ingesta cáustica, y traumatismos, sin antecedentes de déficit neurológico ni trastornos de motilidad esofágica ni procesos otorrinolaringológicos inflamatorios o infecciosos previos. En la tomografía se corrobora perforación esofágica superior con disección enfisematosa cervical y torácica secundaria y presencia de un absceso mediastinal organizado con múltiples septos en su interior con volumen calculado de $600 \mathrm{~mL}$ de material purulento que excluye el lumen esofágico sin comprometer la vía aérea (Figura 2).

Para precisar el sitio de la potencial perforación esofágica se realizó un estudio endoscópico digestivo superior que se documenta en región lateral izquierda e inmediatamente superior a esfínter cricofaríngeo en hipofaringe, sitio de perforación con emisión de exudado purulento por donde se avanza a través del canal de trabajo $20 \mathrm{~cm}$ de una sonda de aspiración tipo Fogarty de 3 French obteniéndose 50 $\mathrm{mL}$ de pus y residuos necróticos (Figura 3).

Por considerar la vía transendoscópica insuficiente para el drenaje de la cavidad mediastinal septada se lleva a cabo un abordaje cervical posterior izquierdo convencional que permitió un desbridamiento mecánico e irrigación exhaustiva con solución fisiológica salina de todo el absceso cervicomediastinal de $500 \mathrm{~mL}$ de material purulento. No fue posible el cierre primario de la perforación de $2 \mathrm{~cm}$ por la excesiva respuesta fibrótica y bordes faringoesofágicos necróticos con mala irrigación. Se colocó un drenaje cervical de Penrose simple y otro drenaje dual para irrigacióndrenaje hacia la cavidad del absceso mediastinal. En el mismo tiempo quirúrgico se ejecutó una gastrostomía con funduplicatura antirreflujo para apoyar la rehabilitación esofágica y nutricional futuras. Inició ayuno con nutrición parenteral por cinco días, antibióticos con ceftriaxona y clindamicina por 21 días e irrigación diaria de la sonda dual mediastinal con mejoría clínica (Figura 4).

Con dos semanas de irrigación y drenaje se eliminó el gasto purulento, se retiró la sonda dual dirigida a mediastino y se corroboró la involución del absceso en la tomografía. Al persistir el trayecto fistuloso faringocutáneo con gasto de saliva como una verdadera esofagostomía
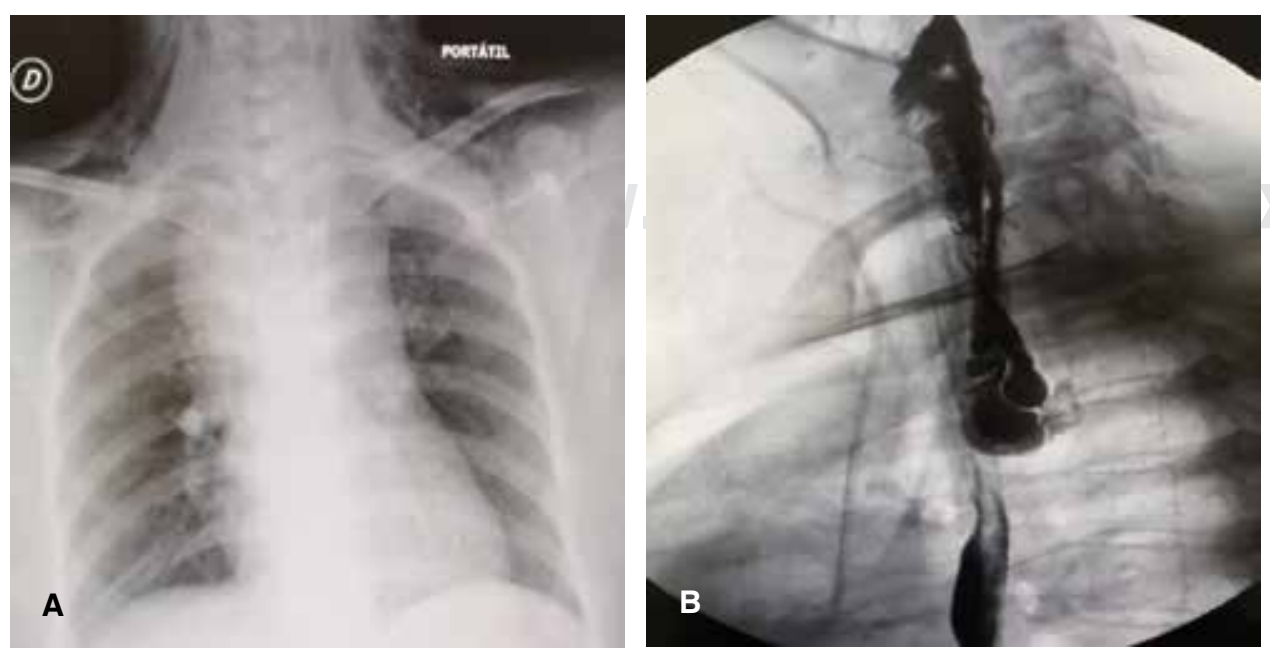

Figura 1:

A) Radiografía torácica simple con enfisema subcutáneo cervical y ensanchamiento mediastinal. B) Esofagograma oral con fuga de material de contraste en esófago cervical izquierdo con extensión a mediastino sugerente de perforación esofágica cervical espontánea con mediastinitis. 
Figura 2:

A) En la tomografía axial con enfisema subcutáneo periesofágico que diseca las vainas profundas cervicales y neumomediastino. B) Absceso mediastinal con extensión a la carina y grandes vasos, presencia de septos en su interior y exclusión de lumen esofágico. C) La tomografía coronal muestra el absceso mediastinal con volumen calculado en $600 \mathrm{~mL}$. D) El absceso con extensión a mediastino posterior con extravasación de medio de contraste con exclusión y compresión extrínseca del lumen esofágico.
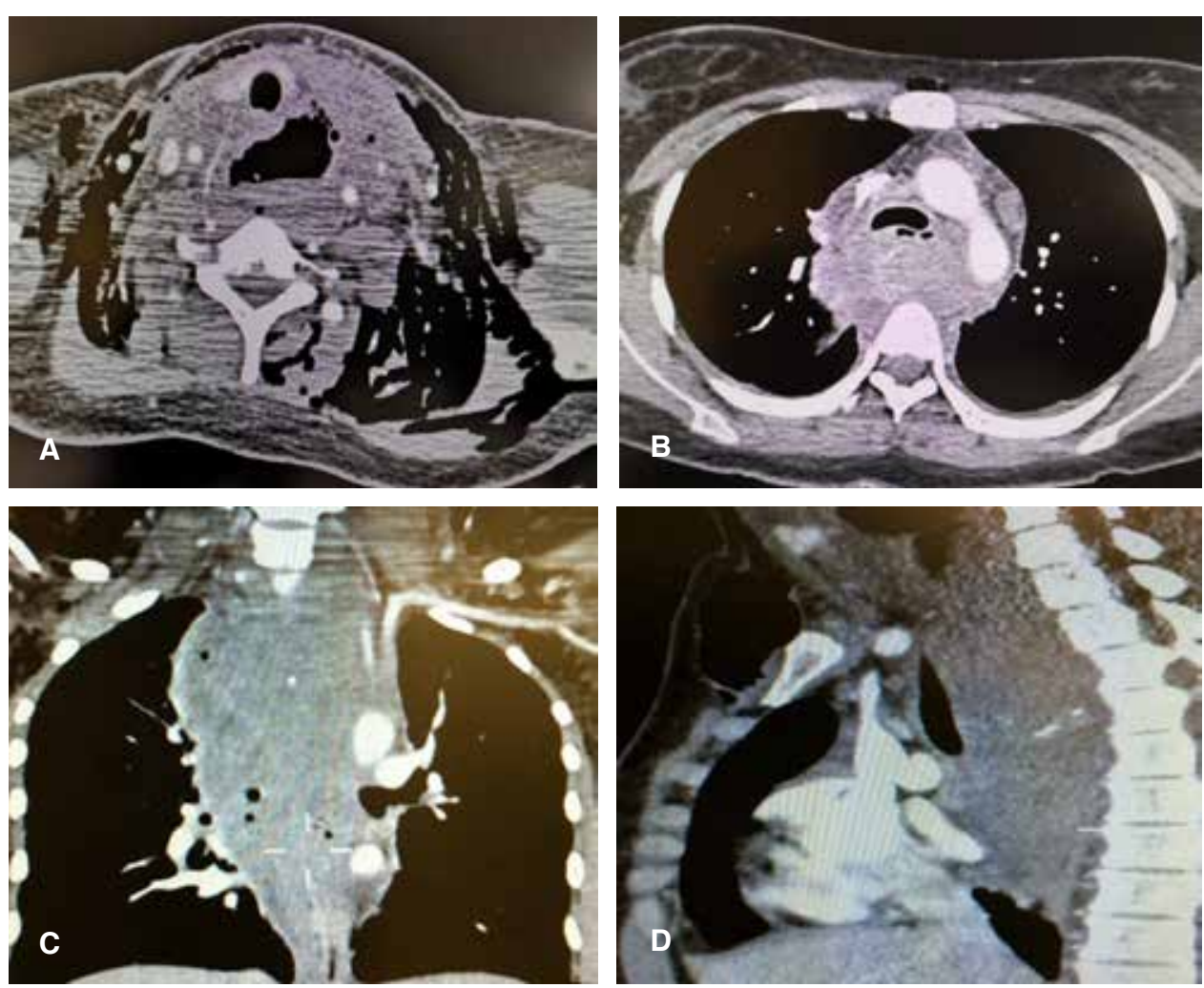

cervical (en el tracto del drenaje de Penrose simple) se realizó nueva endoscopia digestiva superior con paso a estómago sin estenosis residuales y con la presencia de un doble trayecto fistuloso: uno faringocutáneo comunicado al exterior largo y otro faringomediastinal comunicado al interior del mediastino corto de $2 \mathrm{~cm}$. La cavidad mediastinal con tendencia hacia la obliteración por tejido de granulación permitió instilar por vía endoscópica a través del canal de trabajo con un catéter de 3 French una solución de cianoacrilato $10 \mathrm{~mL}$ como adhesivo tisular en el interior de todo el doble trayecto fistuloso, disminuyendo notablemente el gasto de saliva por la fístula faringocutánea hasta su cierre completo una semana después. En la evolución posterior no hubo disfagia, tolerando la vía oral, y control con serie esofagogastroduodenal sin secuelas ni complicaciones (Figura 5).

\section{DISCUSIÓN}

La perforación faringoesofágica comúnmente obedece a causas traumáticas o iatrogénicas (instrumentación endoscópica, intubación endotraqueal difícil y otros procedimientos locorregionales), por lo regular estas lesiones podrían manejarse con opciones conservadoras no quirúrgicas. ${ }^{9-11}$

La perforación faringoesofágica espontánea es rara, el seno piriforme en la base de la lengua y la ausencia de reforzamiento estructural en la disposición de las capas musculares longitudinales de la pared faringoesofágica posterior podrían predisponer a la perforación faríngea después de un incremento súbito de la presión regional por vómitos incoercibles como se explicaría en nuestra paciente. Esta predisposición se reconoce mejor en la pared lateral izquierda del esófago torácico inferior (síndrome de Boerhaave), y es obligatorio identificar etiologías acompañantes como ulceración, malignidad o un proceso inflamatorio e infeccioso. . $^{12,13}$

En nuestro reporte no se logró identificar causas traumáticas o iatrogénicas que explicaran la perforación faringoesofágica, ni antecedentes de disfagia, ni trastornos neuromusculares o de motilidad esofágica, tampoco ingestión o aspiración de cuerpos extraños como las etiologías reconocidas con más frecuencia en la población infantil. Empero, en nuestro caso se consideró la posibilidad de una perforación esofágica cervical por la presencia súbita de toxicidad con respuesta inflamatoria sistémica, dolor cervical y torácico con enfisema subcutáneo y antecedentes con vómitos incoercibles (tríada de Boerhaave)..$^{14} \mathrm{El}$ dolor es el síntoma más común y está usualmente referido al sitio de la perforación.

En las perforaciones cervicales el dolor puede estar acompañado de tumefacción e hipersensibilidad del músculo esternocleidomastoideo; ${ }^{15}$ un diagnóstico tardío de más de 24 horas posterior a la perforación está asociado a un incremento de la morbilidad y mortalidad. ${ }^{14,16}$ El diagnóstico 
temprano requiere un alto índice de sospecha, en el cual el enfisema es corroborado por la radiología simple y la evaluación tomográfica del cuello y tórax, como en nuestro reporte un trago de medio de contraste hidrosoluble confirma el diagnóstico y define el sitio exacto de la perforación. ${ }^{16,17}$ Aunque las complicaciones respiratorias e intratorácicas no son frecuentes en la perforación faringoesofágica ( $10 \%$ con respecto a las perforaciones esofágicas torácicas de $50 \%$ ), el ensanchamiento mediastinal y el enfisema subcutáneo de la radiología simple de cuello y tórax permitieron identificar y diseñar el algoritmo terapéutico del absceso mediastinal detectado por la tomografía. ${ }^{17}$ Las anteriores consideraciones asociadas al sitio de perforación en la pared lateral de la hipofaringe podrían obedecer a un incremento súbito de la presión en la orofaringe e hipofaringe como resultado de una incoordinación neuromuscular y falla en el mecanismo de relajación del músculo cricofaríngeo, y explicar esta predisposición a la perforación faringoesofágica espontánea de nuestra paciente y de otros reportes previamente descritos. ${ }^{12,18-21}$

La mediastinitis se refiere a una inflamación severa del tejido conectivo localizado en la cavidad torácica, ésta podría involucrar la formación de un absceso mediastinal y en $20 \%$ de los casos instaurar una infección polimicrobiana difusa denominada mediastinitis necrotizante descendente (MND). ${ }^{22}$ Esta MND es una infección crítica que involucra su origen en el cuello por causas odontogénicas (de 36 a 47\%), faríngeas (de 33 a $45 \%$ ), cervical (15\%) y otras infecciones de cabeza y cuello (5\%) con rápida progresión por el tejido subcutáneo y la fascia cervical hacia la cavidad mediastinal causando una mortalidad hasta de $40 \%$ por sepsis y falla orgánica múltiple. ${ }^{22-24}$ Esta condición fue descartada en nuestra paciente al no mostrar dos de los cuatro criterios diagnósticos para MND: 1) sepsis severa (presente); 2) demostración radiológica (presente); 3) infección mediastinal necrotizante en el transoperatorio (ausente); y 4) infección orofaríngea y cervical relacionada con la MND (ausente). ${ }^{24,25}$ Esta distinción de la MND con el apoyo de la tomografía y los marcadores inflamatorios (leucocitosis y velocidad de sedimentación globular incrementada VSG) definen la guía estandarizada del tratamiento siempre quirúrgico de la MND con base en la clasificación anatómica de Endo:
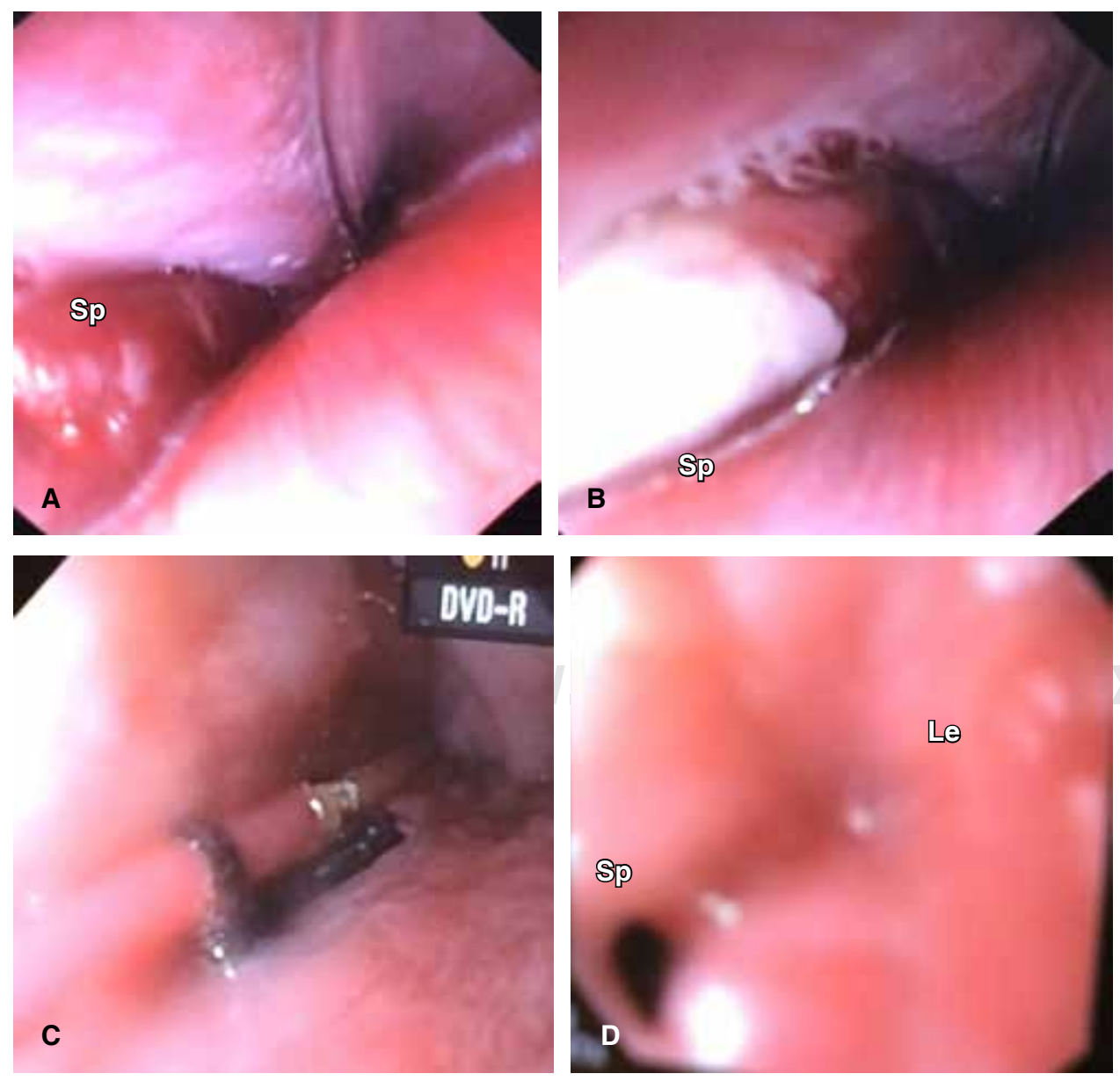

Figura 3:

A) Estudio endoscópico digestivo superior que se documenta en región lateral izquierda e inmediatamente superior a esfínter cricofaríngeo en hipofaringe, sitio de perforación (Sp).

B) Emisión de exudado purulento por el Sp. C) Se avanzan a través del sitio de perforación $20 \mathrm{~cm}$ de una sonda de aspiración tipo Fogarty de 3 French hacia el absceso mediastinal obteniéndose $50 \mathrm{~mL}$ de pus y residuos necróticos. D) Lumen esofágico (Le) y sitio de perforación (Sp) posterior al drenaje transendoscópico. 

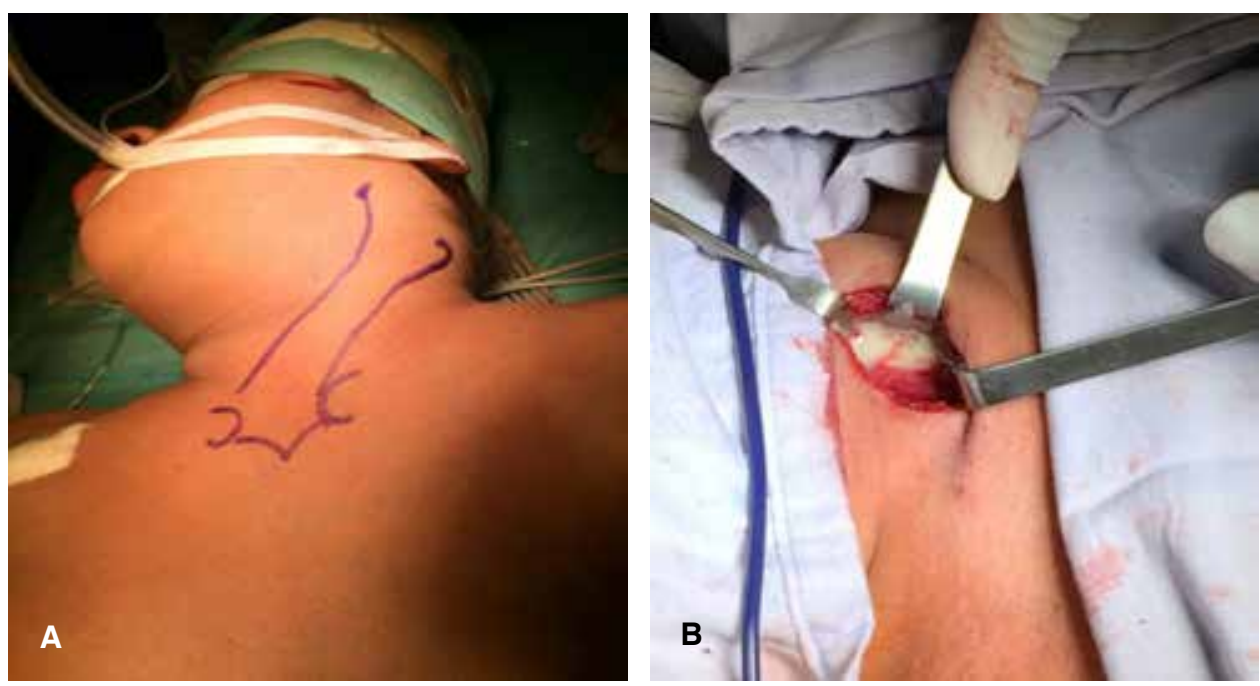

Figura 4:

A) Abordaje cervical posterior izquierdo. B) Desbridamiento mecánico

y drenaje de $500 \mathrm{~mL}$ de material purulento. C) Se decide colocar un drenaje cervical de Penrose (dP) y otro drenaje mediastinal (dm) para irrigación-drenaje hacia cavidad del absceso mediastinal (Am). D) Irrigación diaria por el drenaje mediastinal (dm) hasta su aclaramiento.
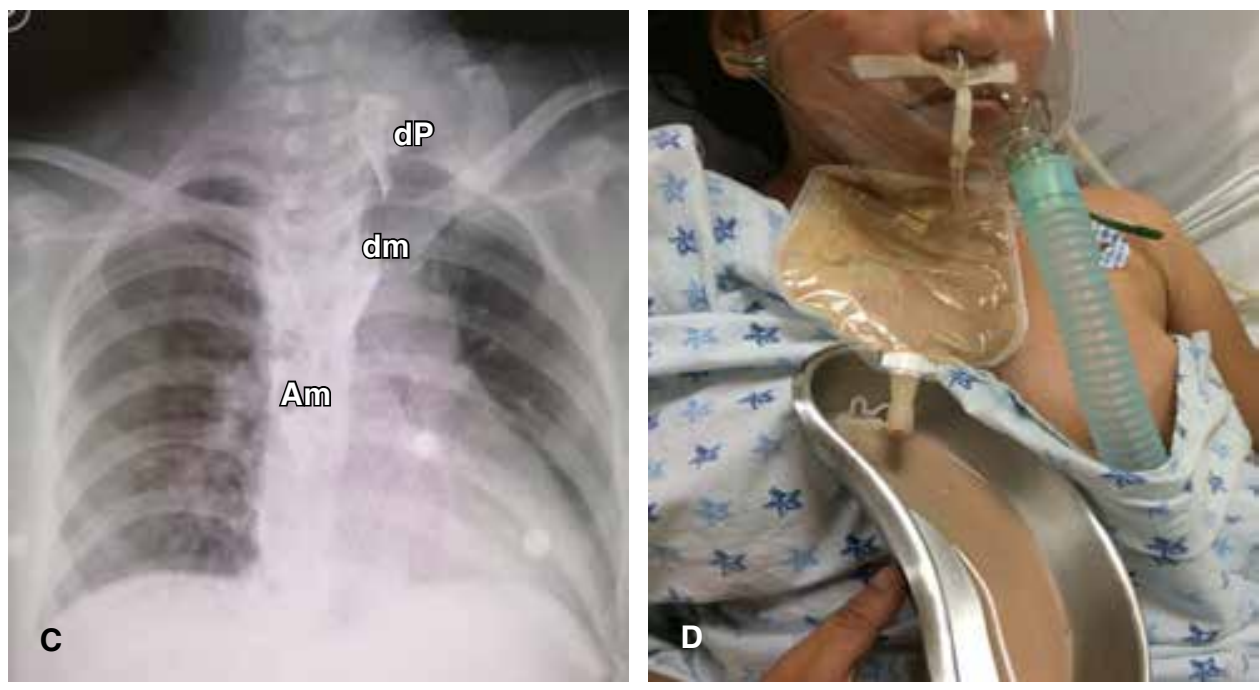

Tipo I (forma localizada): infección por arriba de la carina que involucra el mediastino superior, requiere de un drenaje y desbridamiento quirúrgicos por abordaje cervical único.

Tipo II (forma difusa): infección por debajo de la carina, la cual es subdividida en tipo II A con extensión al mediastino anterior e inferior donde se recomienda un abordaje cervical más transcervical del mediastino valorando una aproximación mixta mediante toracoscopia, mediastinoscopia, inclusive subxifoideo y/o esternotomía que garanticen un drenaje y desbridamiento quirúrgicos completos, un drenaje prolongado con irrigación o succión negativa o la inserción de un drenaje pleural con exposición de una herida abierta para futura granulación aséptica son otras medidas complementarias recomendadas.

Tipo /l B: infección difusa por debajo de la carina con extensión al mediastino posterior e inferior donde se recomienda un abordaje cervical más un transtorácico posterolateral, inclusive bilateral anterior y extendido tipo almeja (clamshell). ${ }^{24,26,27}$
Es de vital importancia lograr el drenaje quirúrgico completo de la MND y el absceso mediastinal secundario en las primeras horas de la atención médica, así como la instauración del tratamiento médico y quirúrgico de la etiología orofaríngea y cervical desencadenantes. La vigilancia estrecha es prioritaria, pues ante la ausencia de mejoría clínica en las 48-72 horas posteriores a la cirugía se deberá revalorar con tomografía de cuello y tórax con marcadores inflamatorios elevados, la posibilidad de una reexploración quirúrgica en caso de sepsis y absceso localizado y persistente. ${ }^{24}$

Para el absceso mediastinal secundario a perforación esofágica, como corresponde a nuestro caso, la aproximación quirúrgica es aceptablemente indicada, si bien ésta no siempre es una opción viable por el riesgo quirúrgico que representa un paciente inestable con choque séptico y otras comorbilidades. En el curso histórico de mejorar las condiciones clínicas para un abordaje quirúrgico se empezó a reportar la utilidad de las intervenciones conservadoras 
con la inserción de drenajes mediastinales por métodos percutáneos y endoscópicos.

El éxito de estas intervenciones conservadoras dependerá de la ejecución de cuatro principios quirúrgicos: 1) reconocimiento temprano de la perforación esofágica (primeras 24 horas); 2) asegurar el desbridamiento y lavado agresivo de la cavidad infectada; 3 ) un período apropiado de drenaje e irrigación; y 4) favorecer el cierre espontáneo de la perforación y/o con la asistencia de un sellante o adhesivo tisular. ${ }^{28}$ Varios reportes sugieren que la perforación cervical tiene mejor respuesta que las torácicas, éstas últimas podrían no cumplir los principios quirúrgicos de éxito por el diagnóstico tardío y la formación de septos fibrosos que dificultan el drenaje completo de la cavidad infectada.

La presencia de un absceso mediastinal en el curso de una perforación esofágica debe denotar un diagnóstico tardío de la misma, la cual podría condicionar un drenaje incompleto de la cavidad septada a través del abordaje transesofágico endoscópico, como ocurrió inicialmente con nuestra paciente, y requerir un abordaje abierto transcervical para complementar el drenaje focalizado al mediastino superior y anterior que aseguró el desbridamiento mecánico y el drenaje exitoso de la cavidad mediastinal loculada. Estas condiciones facilitaron el cierre espontáneo de la perforación faringoesofágica y posteriormente, el cierre de la fístula faringomediastinal.

Hacia la década de los años 80 se empezaron a reportar las inserciones exitosas de drenajes percutáneos en el interior de los abscesos mediastinales guiados por tomografía. ${ }^{29}$ Estos drenajes son ejecutados con técnica de Seldinger y se requiere la corrección de la coagulopatía e intentar mantener recuento plaquetario mayor de 50,000 plaquetas/mL y con ello no retrasar la evacuación y la progresión del deterioro sistémico y endotelial por la sepsis. Se ha reportado $96 \%$ de éxito en estos drenajes percutáneos sin necesidad de subsecuentes intervenciones, los procedimientos fallidos o que requieren segundas intervenciones están relacionados con abscesos mediastinales loculados
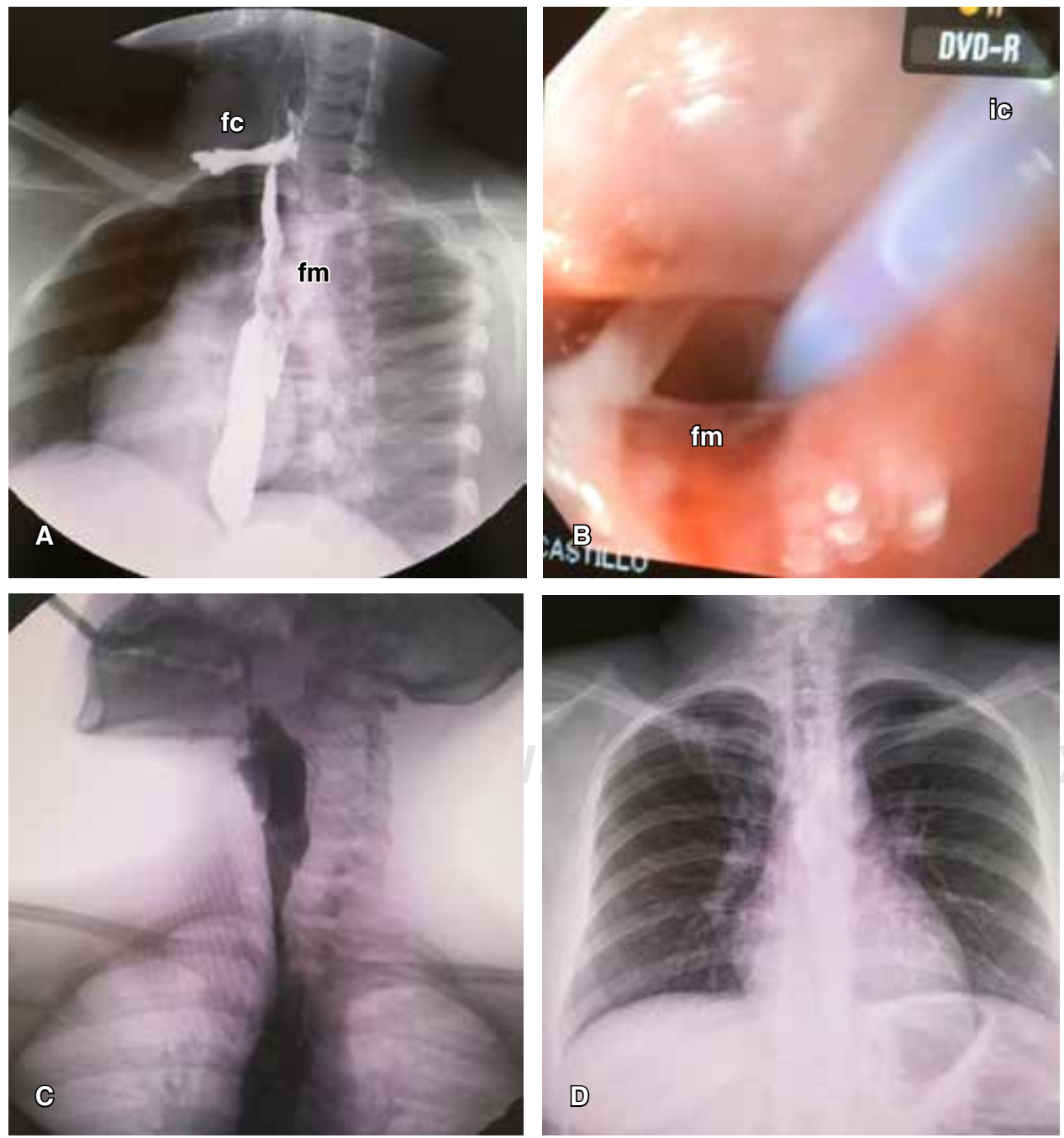

Figura 5:

A) Esofagograma que muestra un doble trayecto fistuloso: uno faringocutáneo $(\mathrm{fc})$ comunicado al exterior y otro faringomediastinal (fm) comunicado al interior del mediastino. B) Instilación por vía endoscópica a través de un catéter 3 French solución de cianoacrilato como adhesivo tisular en el interior del doble trayecto fistuloso (ic). C) Cierre completo del doble trayecto fistuloso una semana después. D) Evolución clínica y radiológica favorables sin secuelas ni complicaciones. 
como en nuestro reporte; no obstante, podrían ser una opción inicial razonable en los pacientes con inestabilidad hemodinámica que no podrían tolerar la intervención quirúrgica. ${ }^{30}$

Otros métodos descritos han sido los drenajes transesofágicos guiados por fluoroscopia, los endoscópicos y los percutáneos-endoscópicos combinados; $;$, $28,31,32$ estos últimos insisten en un drenaje y desbridamiento agresivo del mediastino a través del sitio de la perforación esofágica como se intentó inicialmente en nuestro paciente y la subsecuente irrigación de la cavidad con solución de yodopovidona diluida, inclusive la instilación de algún fibrinolítico, medidas adicionales de las cuales no somos partidarios, pues podrían empeorar la respuesta inflamatoria local y sistémica de nuestros pacientes pediátricos. Los primeros reportes del acceso endoscópico describen la inserción transesofágica de un drenaje nasomediastinal complementado con la guía del ultrasonido. ${ }^{6,8}$ Sin embargo, el depósito de detritus o necrosis sólida en el interior del absceso mediastinal representa factores de fracaso o la indicación de múltiples sesiones de desbridamiento transendoscópico, o bien de un manejo quirúrgico más agresivo. Una vez asegurados los principios quirúrgicos previamente descritos, estos defectos podrían cerrarse con endoclips, stents, adhesivos de fibrina, o bien el cierre espontáneo. Se ha descrito una mortalidad de $7 \%$ por embolismo pulmonar en los adultos sometidos a este desbridamiento endoscópico. ${ }^{3}$

Como complicación del drenaje e irrigación prolongados a través del abordaje cervical, nuestra paciente desarrolló una fístula doble y compleja faringocutánea y faringomediastinal refractaria al cierre espontáneo que requirió la instilación única y exitosa de un adhesivo tisular (cianoacrilato) por abordaje transendoscópico desde el epitelio faringoesofágico hasta el epitelio cutáneo y por todo el trayecto fistuloso hacia el mediastino. El cianoacrilato es un adhesivo sintético que se solidifica en contacto con la sangre, éste puede mezclarse con lipiodol para retrasar la solidificación y facilitar la administración por vía endoscópica y con ello reducir el riesgo de adherencia a los catéteres o al canal de trabajo del endoscopio. Se recomienda la inyección rápida de $1 \mathrm{~mL}$ del adhesivo para disminuir el riesgo de embolización. El cianoacrilato ha mostrado eficacia de 80 a $90 \%$ en la hemostasia inicial de várices gástricas, podría ser más efectivo que la ligadura con banda, la escleroterapia con alcohol o la terapia farmacológica con betabloqueadores, aunque en las várices esofágicas el índice de sangrado recurrente parece ser mayor. Esta eficacia se ha extrapolado al control hemostático de tumores gastrointestinales y úlceras duodenales, así como en el tratamiento endoscópico de fugas biliares refractarias, fístula pancreática y otras enterocutáneas. Sin embargo, no existen estudios controlados que avalen su eficacia en las series de casos descritos; se ha llegado a reportar dolor y fiebre después de la inyección de cianoacrilato en $90 \%$ de los pacientes. Los sellantes de fibrina (componentes reconstituidos de fibrinógeno con factor XIII y trombina humanos) han reportado ser eficaces en el control hemostático de hemorragia variceal, en el cierre de fístulas anales, gastrocutáneas y enterocutáneas y como promotores de cierre de perforaciones esofágicas; salvo el riesgo de anafilaxia y la diseminación de un proceso infeccioso los sellantes de fibrina son bien tolerados.

Extrapolado a las circunstancias de la perforación faringoesofágica que se complicó en nuestra paciente con una fístula faringocutánea y faringomediastinal residuales, sólo existen reportes aislados exitosos posteriores a la inyección endoscópica de monómero de alfacianoacrilato para el cierre de fístulas esofágicas de etiología traumática, anastomótica y neoplásica. En la población pediátrica se ha descrito la utilidad del cianoacrilato Glubran 2 en el tratamiento endoscópico de tres fístulas traqueoesofágicas recurrentes posterior a la epitelización con diatermia e inyecciones repetidas en cuatro semanas; la resolución quirúrgica con la aplicación de tejido vascularizado es superior a estas propuestas endoscópicas.

\section{CONCLUSIONES}

Existe poco sustento bibliográfico que apoye la recomendación del uso de cianoacrilato y sellantes de fibrina como promotores del cierre de perforaciones faringoesofágicas. El éxito de nuestro reporte obedece a la aplicación de los principios quirúrgicos de reconocimiento temprano de la perforación, desbridamiento agresivo y apropiado drenaje como promotores del cierre espontáneo local favorecido por las propiedades adhesivas del cianoacrilato.

\section{REFERENCIAS}

1. Zwischengerger JB, Alpard SK, Orringer MB. Esophagus. In: Townsend CM Jr, editor. Sabiston textbook of surgery. $16^{\text {th }}$ ed. Philadelphia: Saunders; 2001. p. 723-727.

2. Dolgin SR, Wykoff TW, Kumar NR, Maniglia AJ. Conservative medical management of traumatic pharyngeoesophageal perforations. Ann Otol Rhinol Laryngol. 1992;101(3):209-215. https://doi. org/10.1177/000348949210100303.

3. Wehrmann T, Stergiou N, Vogel B, Riphaus A, Köckerling F, Frenz MB. Endoscopic debridement of paraesophageal, mediastinal abscesses: a prospective case series. Gastrointest Endosc. 2005;62(3):344-349. https://doi.org/10.1016/j.gie.2005.03.001.

4. White RK, Morris DM. Diagnosis and management of esophageal perforations. Am Surg. 1992;58(2):112-119.

5. Muir AD, White J, McGuigan JA, McManus KG, Graham AN. Treatment and outcomes of oesophageal perforation in a tertiary referral centre. Eur J Cardiothorac Surg. 2003;23(5):799-804. https://doi.org/10.1016/ s1010-7940(03)00050-2.

6. Abe M, Sugiyama M, Hashimoto Y, Itoh N, Nakaura H, Izumisato Y, et al. Endoscopic nasomediastinal drainage followed by clip application for treatment of delayed esophageal perforation with mediastinitis. 
Gastrointest Endosc. 2001;54(5):646-648. https://doi.org/10.1067/ mge.2001.117155.

7. Kanshin NN, Pogodina AN. Transesophageal drainage of the mediastinum in perforating mediastinitis. Vestn Khir Im II Grek. 1983;130(2):24-27.

8. Kahaleh M, Yoshida C, Kane L, Yeaton P. EUS drainage of a mediastinal abscess. Gastrointest Endosc. 2004;60(1):158-160. https://doi. org/10.1016/s0016-5107(04)01310-0.

9. Eichhorn KWG, Bley TA, Ridder GJ. Undeteced hypopharyngeal perforation with deep neck abscess and mediastinitis due to transesophageal echocardiography. HNO. 2003;51(11):903-907. https://doi. org/10.1007/s00106-003-0809-y

10. Heater DW, Haskvitz L. Suspected pharyngoesophageal perforation after a difficult intubation: a case report. AANA J. 2005;73(3):185-187.

11. Salemis NS, Georgiou C, Alogdianakis E, Gourgiotis S, Karalis G. Hypopharyngeal perforation because of blunt neck trauma. Emerg Radiol. 2009;16(1):71-74. https://doi.org/10.1007/s10140-007-0699-5.

12. Roh JL, Park Cl. Spontaneous pharyngeal perforation after forceful vomiting: the difference from classic Boerhaave's syndrome. Clin Exp Otorhinolaryngol. 2008;1(3):174-176. https://doi.org/10.3342/ ceo.2008.1.3.174.

13. Brinster CJ, Singhal S, Lee L, Marshall MB, Kaiser LR, Kucharczuk JC. Evolving options in the management of esophageal perforation. Ann Thorac Surg. 2004;77(4):1475-1483. https://doi.org/10.1016/j. athoracsur.2003.08.037.

14. Bjerke HS. Boerhaave's syndrome and barogenic injuries of the esophagus. Chest Surg Clin N Am. 1994;4(4):819-825.

15. Younes Z, Johnson DA. The spectrum of spontaneous and iatrogenic esophageal injury: perforations, Mallory-Weiss tears, and hematomas. J Clin Gastroenterol. 1999;29(4):306-317. https://doi. org/10.1097/00004836-199912000-00003.

16. Gupta NM, Kaman L. Personal management of 57 consecutive patients with esophageal perforation. Am J Surg. 2004;187(1):58-63. https://doi.org/10.1016/j.amjsurg.2002.11.004.

17. Shaligram A, Dugar N, Capper R. Perforation of cervical oesophagus. J Laryngol Otol. 2005;119(1):51-53. https://doi. org/10.1258/0022215053222987.

18. Bradham RR, deSaussure C, Lemel AL. Spontaneous perforation of the cervical esophagus. Arch Surg. 1976;111(3):284-285. https://doi. org/10.1001/archsurg.1976.01360210078015.

19. Agada FO, Dalati MHN, Lee CA, Coatesworth AP, Grace ARH. Spontaneous rupture of the cervical oesophagus following nose blowing: a case report. Int J Clin Pract Suppl. 2005;(147):43-44. https://doi. org/10.1111/j.1742-1241.2004.00270.x.

20. Fraser ID, Williams GT. Spontaneous rupture of the pharynx. J Laryngol Otol. 1975;89(3):317-322. https://doi.org/10.1017/ s0022215100080415.
21. Wake M, Stansbie M, Thompson H. Spontaneous perforation of the pharynx/esophagus. Ear Nose Throat J. 1991;70(5):318-320.

22. Kocher GJ, Hoksch B, Caversaccio M, Wiegand J, Schmid RA. Diffuse descending necrotizing mediastinitis: surgical therapy and outcome in a single-centre series. Eur J Cardiothorac Surg. 2012;42(4):e66-72. https://doi.org/10.1093/ejcts/ezs385.

23. Misthos P, Katsaragakis S, Kakaris S, Theodorou D, Skottis I. Descending necrotizing anterior mediastinitis: analysis of survival and surgical treatment modalities. J Oral Maxillofac Surg. 2007;65(4):635-639. https://doi.org/10.1016/j.joms.2006.06.287.

24. Prado-Calleros HM, Jiménez-Fuentes E, Jiménez-Escobar I. Descending necrotizing mediastinitis: Systematic review on its treatment in the last 6 years, 75 years after its description. Head Neck. 2016;38 Suppl:E2275-E2283. https://doi.org/10.1002/hed.24183.

25. Estrera AS, Landay MJ, Grisham JM, Sinn DP, Platt MR. Descending necrotizing mediastinitis. Surg Gynecol Obstet. 1983;157(6):545-552.

26. Endo S, Murayama F, Hasegawa T, Yamamoto S, Yamaguchi T, Sohara $Y$, et al. Guideline of surgical management based on diffusion of descending necrotizing mediastinitis. Jpn J Thorac Cardiovascular Surg. 1999;47(1):14-19. https://doi.org/10.1007/bf03217934.

27. De Freitas RP, Fahy CP, Brooker DS, Primrose WJ, McManus KG, McGuigan JA, et al. Descending necrotising mediastinitis: a safe treatment algorithm. Eur Arch Otorhinolaryngol. 2007;264(2):181-187. https://doi.org/10.1007/s00405-006-0174-z.

28. Hookey LC, Le Moine O, Deviére J. Successful endoscopic management of a cervical pharyngeal perforation and mediastnal abscess. Gastrointest Endosc. 2005;61(1):158-160. https://doi.org/10.1016/ s0016-5107(04)02452-6.

29. Gobien RP, Stanley JH, Gobien BS, Vujic I, Pass HI. Percutaneous catheter aspiration and drainage of suspected mediastinal abscesses. Radiology. 1984;151(1):69-71. https://doi.org/10.1148/radiology.151.1.6701339.

30. Arellano RS, Gervais DA, Mueller PR. Computed tomography-guided drainage of mediastinal abscesses: clinical experience with 23 patients. J Vasc Interv Radiol. 2011;22(5):673-677. https://doi. org/10.1016/j.jvir.2011.01.427.

31. Meranze SG, LeVeen RF, Burke DR, Cope C, McLean GK. Transesophageal drainage of mediastinal abscesses. Radiology. 1987;165(2):395-398. https://doi.org/10.1148/radiology.165.2.3659364.

32. Shenfine J, Hayes N, Richardson DL, Griffin SM. Combined percutaneous-endoscopic management of a perforated esophagus: a novel technique. Gastrointest Endosc. 2001;54(5):649-651. https:// doi.org/10.1067/mge.2001.118718.

Conflicto de intereses: Los autores declaran no tener conflicto de intereses. 